\title{
BMJ Open Cohort Profile: National health insurance service-senior (NHIS-senior) cohort in Korea
}

\author{
Yong Ik Kim, ${ }^{1}$ Yeon-Yong Kim, ${ }^{2}$ Jong Lull Yoon, ${ }^{3}$ Chang Won Won, ${ }^{4}$ Seongjun $\mathrm{Ha},{ }^{2}$ \\ Kyu-Dong Cho, ${ }^{1}$ Bo Ram Park, ${ }^{1}$ Sejin Bae, ${ }^{1}$ Eun-Joo Lee, ${ }^{2}$ Seong Yong Park, ${ }^{1}$ \\ Jong Heon Park, ${ }^{2}$ Kyeong-ran Lee, ${ }^{1}$ Donghun Lee, ${ }^{1}$ Seung-lyeal Jeong, ${ }^{2}$ \\ Hyung-soo Kang ${ }^{1}$
}

To cite: Kim YI, Kim Y-Y, Yoon JL, et al. Cohort Profile: National health insurance service-senior (NHIS-senior) cohort in Korea. BMJ Open 2019;9:e024344. doi:10.1136/ bmjopen-2018-024344

- Prepublication history and additional material for this paper are available online. To view these files, please visit the journal online (http://dx.doi. org/10.1136/bmjopen-2018024344).

Received 22 May 2018 Revised 23 October 2018 Accepted 17 January 2019

Check for updates

C Author(s) (or their employer(s)) 2019. Re-use permitted under CC BY-NC. No commercial re-use. See rights and permissions. Published by BMJ.

${ }^{1}$ National Health Insurance Service, Wonju, Gangwon-do, Republic of Korea

${ }^{2}$ Big Data Steering Department, National Health Insurance

Service, Wonju, Republic of Korea

${ }^{3}$ Hallym University College of Medicine, Chuncheon, Gangwon, Republic of Korea

${ }^{4}$ Kyung Hee University School of Medicine, Seoul, Republic of Korea

Correspondence to

Mr Hyung-soo Kang;

khs0293@nhis.or.kr

\section{ABSTRACT}

Purpose The National Health Insurance Service (NHIS)Senior was set up to provide high-quality longitudinal data that can be used to explore various aspects of changes in the socio-economical and health status of older adults, to predict risk factors and to investigate their health outcomes.

Participants The NHIS-Senior cohort, a Korean nationwide retrospective administrative data cohort, is composed of older adults aged 60 years and over in 2002. It consists of 558147 people selected by $10 \%$ simple random sampling method from a total of 5.5 million subjects aged $60+$ in the National Health Information Database. The cohort was followed up through 2015 for all subjects, except for those who were deceased.

Findings to date The healthcare utilisation and admission rates were the highest for acute upper respiratory infections and influenza $(75.2 \%)$. The age-standardised (defined with reference to the world standard population) mortality rate for 10 years (through 2012) was 4333 per 100000 person-years. Malignant neoplasms were the most common cause of death in both sexes (1032.1 per 100000 person-years for men, 376.7 per 100000 personyears for women). A total of 34483 individuals applied for long-term care service in 2008 , of whom $17.9 \%$ were assessed as grade 1 , meaning that they were completely dependent on the help of another person to live daily life. Future plans The data are provided for the purposes of policy and academic research under the Act on Promotion of the Provision and Use of Public Data in Korea. The NHIS-Senior cohort data are only available for Korean researchers at the moment, but it is possible for researchers outside the country to gain access to the data by conducting a joint study with a Korean researcher. The cohort will be maintained and continuously updated by the NHIS.

\section{INTRODUCTION}

The Republic of Korea (hereafter 'Korea') is experiencing the fastest population ageing among the Organisation for Economic Co-operation and Development countries. ${ }^{1}$ It is projected that the proportion of the elderly -65 years old and over - population,
Strengths and limitations of this study

- It provides reliable data based on a large sample $(n=558147)$ and a long duration of follow-up (from 2002 to 2015), and is representative of the entire elderly population.

- It is possible to analyse the pre-hospital stages of disease using information from the health screening programme and long-term care services.

- The NHIS-Senior cohort has certain limitations. First, some of the subjects did not participate in the health screening programme or receive long-term care services. Second, variables on health behaviours are limited since those data were obtained from self-reporting. Third, the disease codes might not accurately reflect patients' medical conditions.

which was $12.8 \%$ in 2015 , will reach $42.5 \%^{2}$ in 2065 due to a dramatic increase in life expectancy and a sharp decrease in the birth rate. ${ }^{3}$ Increasing population ageing is also a source of economical, health and social burdens. ${ }^{4}$ As the family structure has also rapidly changed, the proportion of elderly people living with adult children decreased from $53.2 \%$ in $1998^{5}$ to $28.6 \%$ in $2008 .^{6}$ Accordingly, the age dependency ratio, defined as the number of individuals aged 65 and over per 100 people of working age, is projected to reach 88.6 in $2065 .^{2}$

In 2008, long-term care insurance (LTCI) was introduced in Korea as a form of social insurance to share caregivers' burden due to functional loss and chronic disease complications. It was organised and planned by the Ministry of Health and Welfare, and has been implemented by the National Health Insurance Service (NHIS) based on the Act on Long-Term Care Insurance for the Senior Citizens. ${ }^{7}$ Since Korea has a single public insurance system that covers medical utilisation for the entire population, it was easier 
Table 1 General characteristics of the national health insurance service-senior (NHIS-Senior) cohort

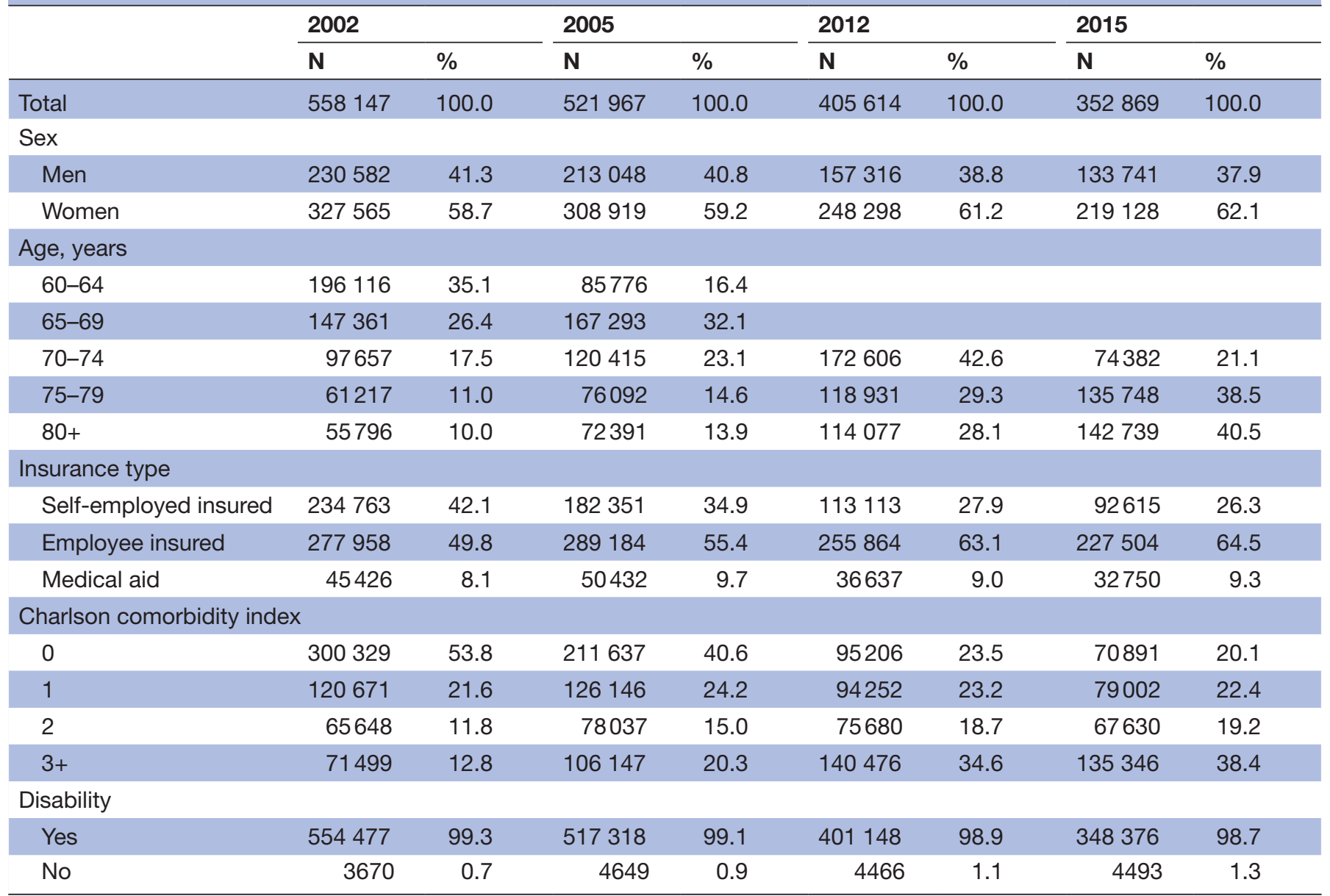

to implement the insurance system using the pre-existing health insurance organisations-the NHIS with 178 branch offices nationwide-than using a tax-based long-term care programme that would need to be newly created. ${ }^{8}$ LTCI provides facility or home care services for the elderly with impairments in activities of daily living. When a person applies for LTCI services, he or she is given a grade based on a comprehensive consideration of cognitive function, activities of daily living and mental and rehabilitation status. The type of service received is determined by the grade. ${ }^{7}$

In 2011, the NHIS established an administrative database for research purposes, the National Health Information Database (NHID), which stores all the records of healthcare and long-term care services. ${ }^{9}$ As the NHIS also provides a national health screening programme that includes medical check-ups every 2 years, data from a self-reported questionnaire (lifestyle, past medical history and family medical history) and measured biometric information (blood pressure, anthropometry, clinical laboratory and urinalysis findings) are included in the NHID. ${ }^{10}$

The NHIS-Senior cohort, a nationwide retrospective cohort, which includes information from elderly individuals randomly sampled by the NHID, was constructed by the Big Data Steering Department of the NHIS head office in 2016. The NHIS-Senior cohort consists of five databases: an eligibility database, a national health screening database, a healthcare utilisation database, a long-term care insurance database and a healthcare provider database. This cohort was set up to provide high-quality longitudinal data that can be used to explore various aspects of changes in the socio-economical and health status of older adults, to predict risk factors and to investigate their health outcomes.

\section{COHORT DESCRIPTION}

\section{The participants of the cohort}

The NHIS-Senior cohort is composed of older adults aged 60 years and over in 2002. It consists of 558147 people selected by $10 \%$ simple random sampling method from a total of 5.5 million subjects aged $60+$ in the NHID (online supplementary table 1 ). The cohort was followed up retrospectively through 2015 for all subjects, except for those who lost eligibility for national health insurance, a compulsory social insurance programme, due to death and emigration, in accordance with the National Health Insurance Act. Emigrants were excluded from the NHIS-Senior cohort because the rate of emigration from Korea is very low ${ }^{11}$ and it is difficult to follow-up emigrants due to the frequent changes in their eligibility. 
离

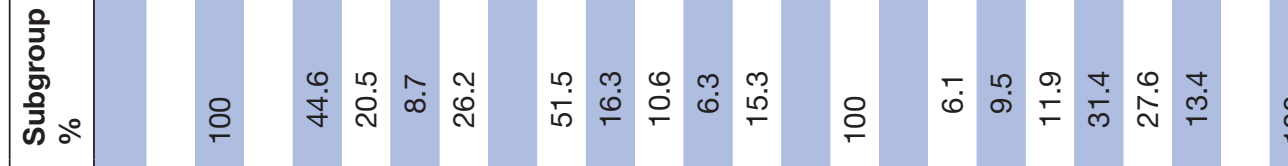

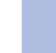

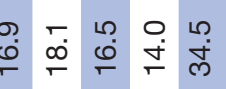



¿ ल

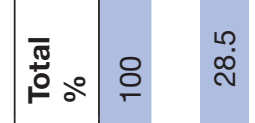

高<smiles>C=CC</smiles>

\section{$\frac{8}{2}$}

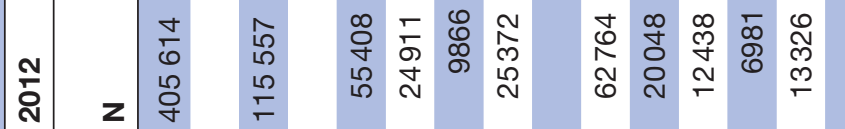

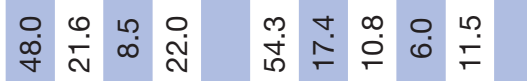

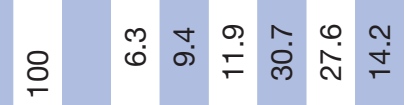

움

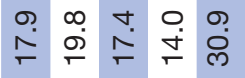



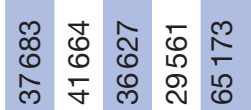
$\stackrel{0}{\circ}$

$\stackrel{\oplus}{\mathfrak{N}}$

竞

岗

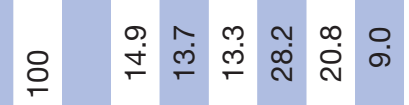

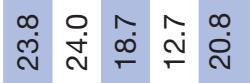

$\stackrel{\text { की }}{\subseteq}$

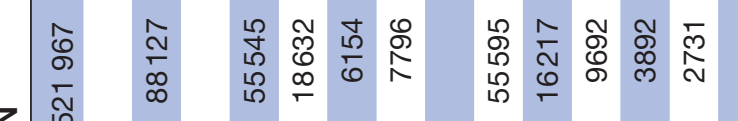

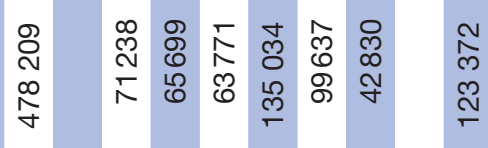

芦

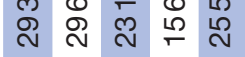




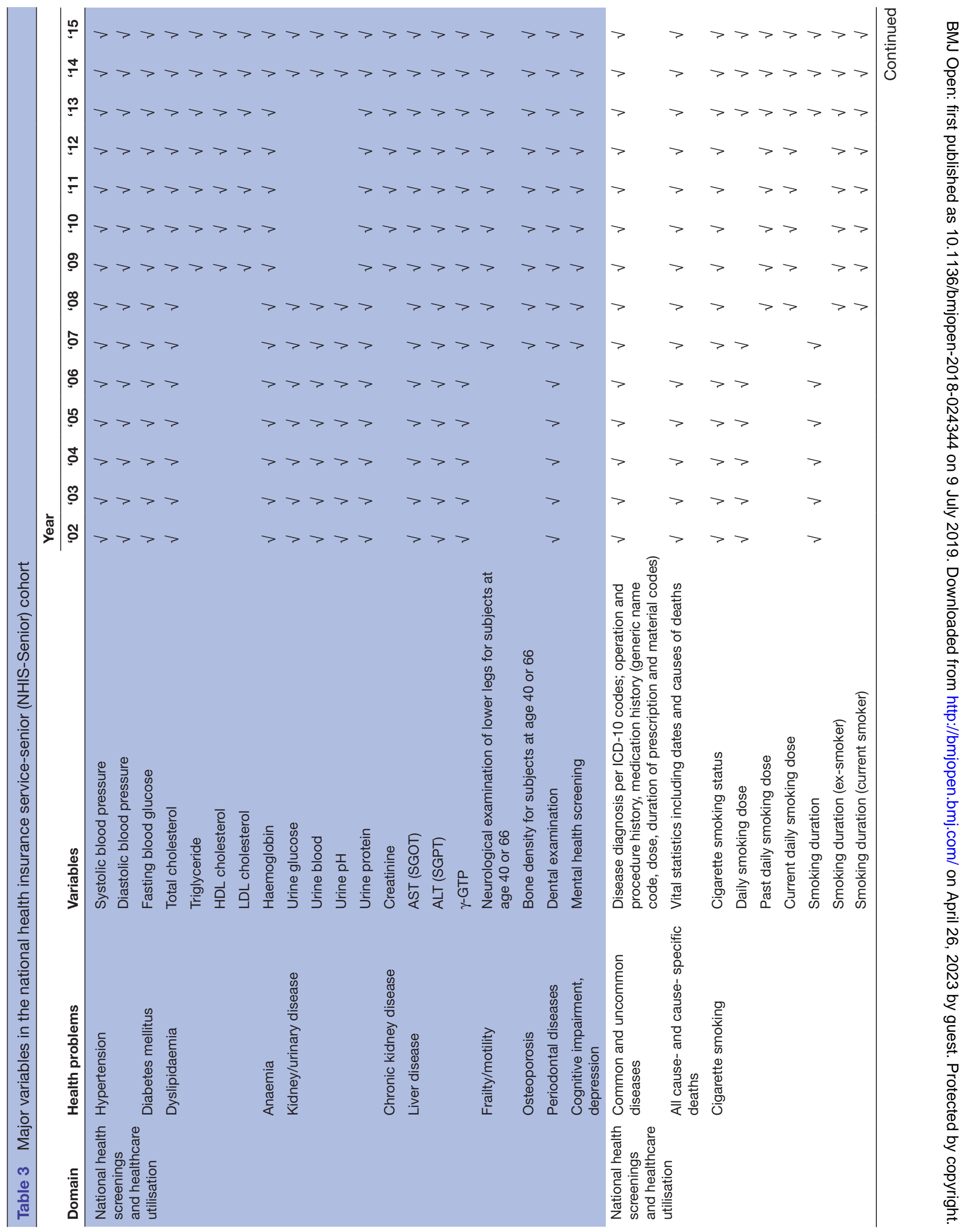




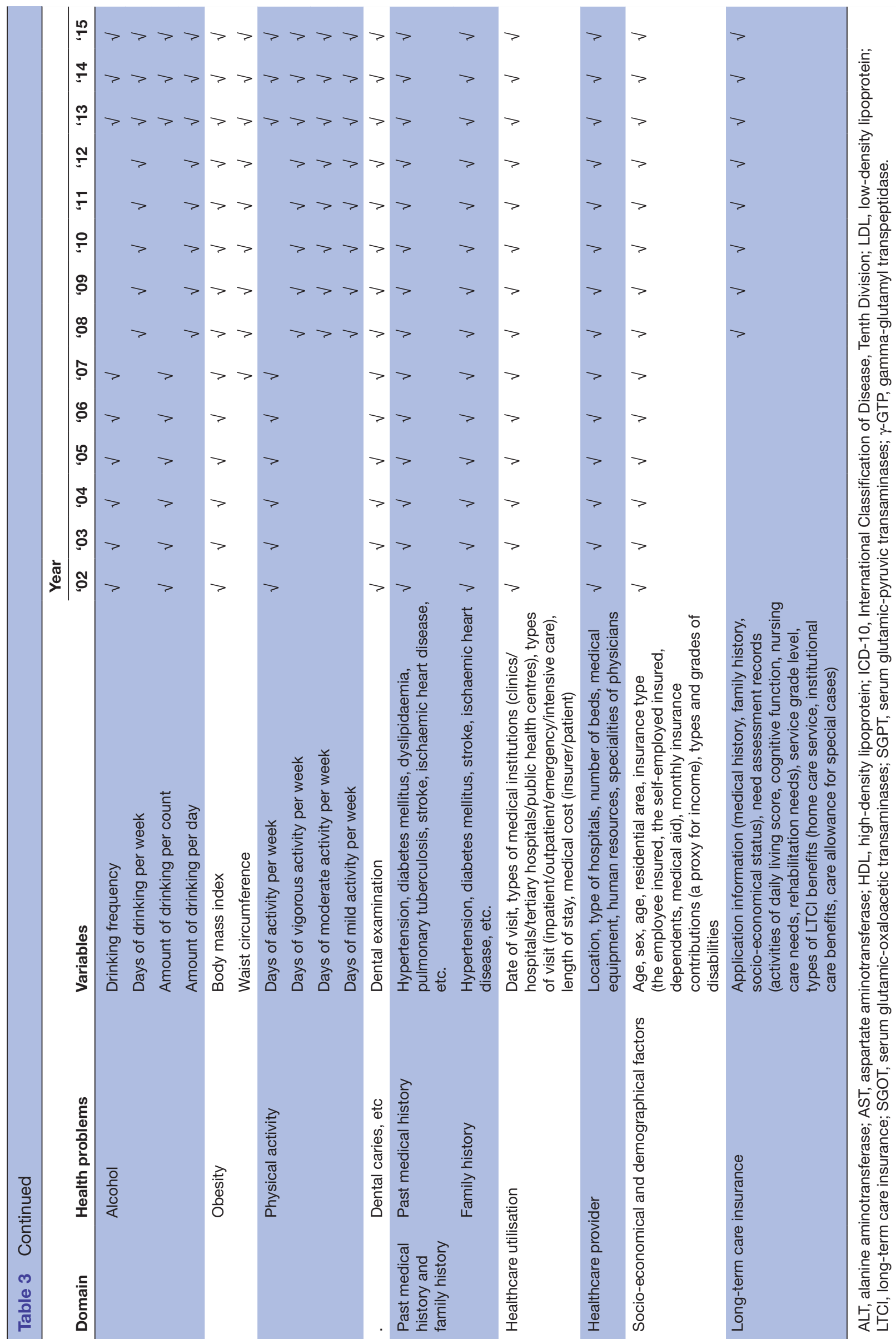






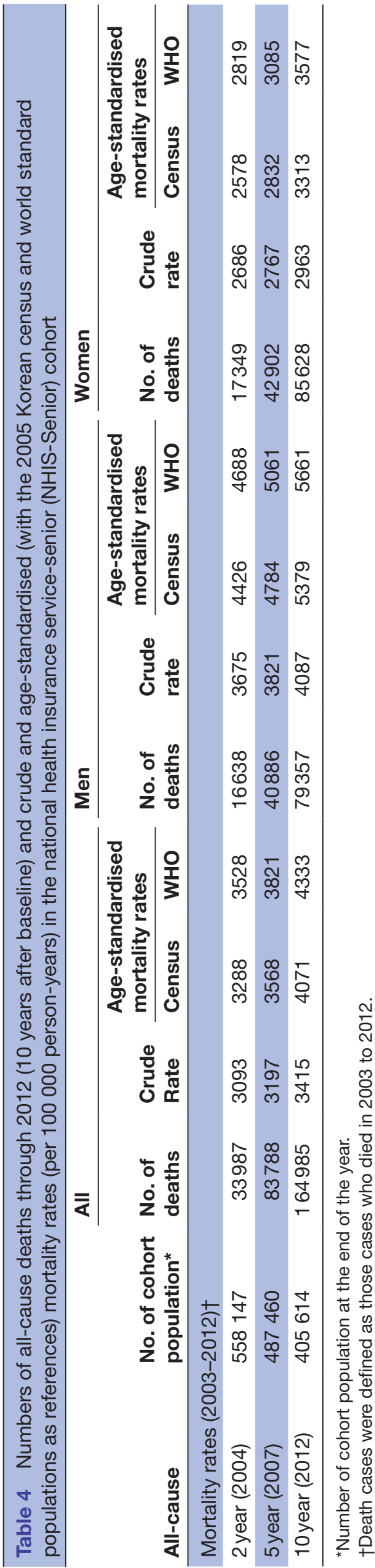

In most studies, the elderly are defined as 65 years old and over; however, the seniors in the NHIS-Senior cohort were defined as those aged 60 and over in order to compare health status before and after 65 years old during the follow-up period. The number of subjects in five databases is presented as online supplementary table 2. In this cohort, the first selected subject was traced and no new subjects were added. Therefore, since the age of 60 years or older was selected as of 2002, the age of subjects in 2015 is 73 years or older. In the NHID, de-identified join keys replacing personal identifiers are used to secure ethical clearance. $^{9}$ Therefore, the researcher cannot receive informed consent from individual patients for the use of personal information. However, the use of NHID for research purposes requires approval (or exemption) from the institutional review board.

The general characteristics of the cohort are shown in table 1 . The total number of the cohort was 558147 at the beginning (2002) and 352869 at the end of the follow-up (2015). The proportion of men, which was $41.3 \%$ in 2002, declined to $37.9 \%$ in 2015 due to higher mortality rates among men. The number of subjects with three points or more on the Charlson comorbidity index, ${ }^{12}$ which was calculated from the International Classification of Disease codes in the healthcare utilisation database every year using comorbidity weights from a previous study, ${ }^{12}$ increased from $12.8 \%$ in 2002 to $38.4 \%$ in 2015 .

The characteristics of the cohort population regarding healthcare utilisation are presented in table 2, and these findings clearly show how the health status of the elderly became worse over the past decade as they aged. The subjects who had ever been admitted to hospital(s) during a year increased from $51515(9.2 \%)$ in 2002 to $108203(30.7 \%)$ in 2015 . The proportion of inpatients hospitalised for 120 days or more per year also increased from $1.3 \%$ in 2002 to $15.3 \%$ in 2015 . Of the cohort population, $95.2 \%$ utilised outpatient medical services in 2015. The number of patients who received prescriptions for over 300 days per year increased from $9.2 \%$ in 2002 to $56.4 \%$ in 2015. Among them, the number of patients whose prescriptions included more than five active ingredients increased from $14.6 \%$ in 2002 to $34.5 \%$ in 2015 .

\section{Follow-up interval}

The cohort has been followed-up through 2015 annually for eligibility information including death information and biennially for information from the health screening programme. The data are based on information collected from various sources. Information on death (date and cause of death) was collected from Statistics Korea. By law, all death certificates must be reported to Statistics Korea. Personal information regarding income deciles based on the insurance contribution imposed, residential area and disability status were collected from the Public Information Sharing System, National Tax Service and Ministry of Health and Welfare of Korea. Information on health screening results was only tracked for those who participated in a health screening programme with 
scheduled check-ups at least every 2 years. The participation rate in the health screening programme was $77.7 \%$ in 2016. ${ }^{13}$ LTCI information was only available for those who applied for these services, which started in July 2008. As the NHIS covers the entire population of Korea as a single public insurer, the healthcare utilisation information includes all medical services (from inpatient, outpatient and pharmacy visits) claimed by healthcare facilities in Korea. Information about the healthcare facilities has been also updated annually.

\section{The key variables}

The key variables of the NHIS-Senior cohort, which were mainly selected from the variables of the NHID, are presented in table 3 . The eligibility database included information about income-based insurance contributions (a proxy for income), demographical variables and date and cause of death. Health-related risk factors obtained using questionnaires (cigarette smoking status/daily amount/duration, frequency per week and amount per day of alcohol drinking (regardless of the type of alcohol), type and days per week of physical activity, past medical history and family history), blood pressure, anthropometry (body mass index and waist circumference) and clinical laboratory results (fasting glucose, lipid profile, haemoglobin, urine stick test results, creatinine levels and liver enzyme levels) were included in the health screening database. Some variables have had changes in their measurement methods during the follow-up period. The healthcare utilisation database was based on data collected during the process of claiming healthcare services and included information on inpatient and outpatient medical services (diagnosis, length of stay, services provided and treatment costs) and prescription records (drug codes, days prescribed and daily dosage). The healthcare provider database included information on the types, personnel and equipment of healthcare facilities. The LTCI database included information on applications for long-term care service and the utilisation of such services (activities of daily living, cognitive function, nursing care needs, rehabilitation needs, service grade and type of service).

\section{Patient and public involvement}

This data set was drawn from a retrospective cohort based on administrative data, and separate patient recruitment procedures were not carried out. As the data were de-identified, the consent of the subject and direct contact were not applicable.

\section{Findings to date}

Since the NHIS-Senior was launched in December 2015, several studies using the NHIS-Senior cohort database have been published. The published studies have examined topics emerging as important issues in Korea, such as the risk of dementia, ${ }^{14-16}$ the risk of osteoporotic fracture and hip surgery ${ }^{17} 18$ and associations of body anthropometry (body mass index and waist circumference) with mortality. ${ }^{19} 20$ Although numerous studies have not yet investigated these issues, other possible topics include functional disabilities and lifestyle modifications in the elderly population. Some studies have used the LTCI database, not the NHIS-Senior cohort, to evaluate the effectiveness of introducing long-term care services. ${ }^{21} 22$

We herein present the basic statistics of the NHIS-Senior cohort for future data users. We calculated the healthcare utilisation and mortality rates. The rates were age-standardised using the census population of Statistics Korea in 2005 and the world standard population. ${ }^{23}$ The rates that were standardised using the world standard population are presented below.

The healthcare utilisation and admission rates of 10 major diseases at baseline are presented in online supplementary tables 3 and 4 . The rates were the highest for acute upper respiratory infections and influenza (75.2\%), followed by disorders of the teeth and supporting structures $(40.8 \%)$ and other diseases of the eye and adnexa $(30.8 \%)$. The mortality rates of the cohort population are presented in table 4 . We calculated mortality rates using the entire sample data of the NHIS-Senior cohort from 2003 to 2012. The age-standardised (defined with reference to the world standard population) mortality rate for the first 2 years (through 2004) was 3528 per 100000 person-years, while the rate for 5 years (through 2007) was 3821 per 100000 person-years and the rate for 10 years (through 2012) was 4333 per 100000 person-years. In men, the mortality rate was higher than in women (2 year mortality rates of 4688 per 100000 person-years for men and 2819 per 100000 person-years for women) $(\mathrm{p}<0.001)$.

The major causes of death during the follow-up period (2003 to 2015) are presented by sex in table 5. Causes of death were classified using the list of 56 causes of death used by Statistics Korea, which was derived from the list of 80 causes of death recommended by the WHO for the tabulation of mortality statistics. Malignant neoplasms were the most common cause of death in both sexes (1032.1 per 100000 person-years for men, 376.7 per 100000 person-years for women). Cerebrovascular diseases were the second most common cause of death in both men (386.0 per 100000 person-years) and women (256.0 per 100000 person-years). Heart disease was the third most common cause of death in both men (247.5 per 100000 person-years) and women (190.8 per 100000 person-years). Diabetes mellitus was the fourth most common cause of death in both men (143.8 per 100000 person-years) and women (101.3 per 100000 person-years).

Information regarding the long-term care service grade and functional impairment score is shown in online supplementary table 5. A total of 34483 individuals applied for long-term care service in 2008, of whom $17.9 \%$ were assessed as grade 1 , meaning that they were completely dependent on the help of another person to live daily life. 


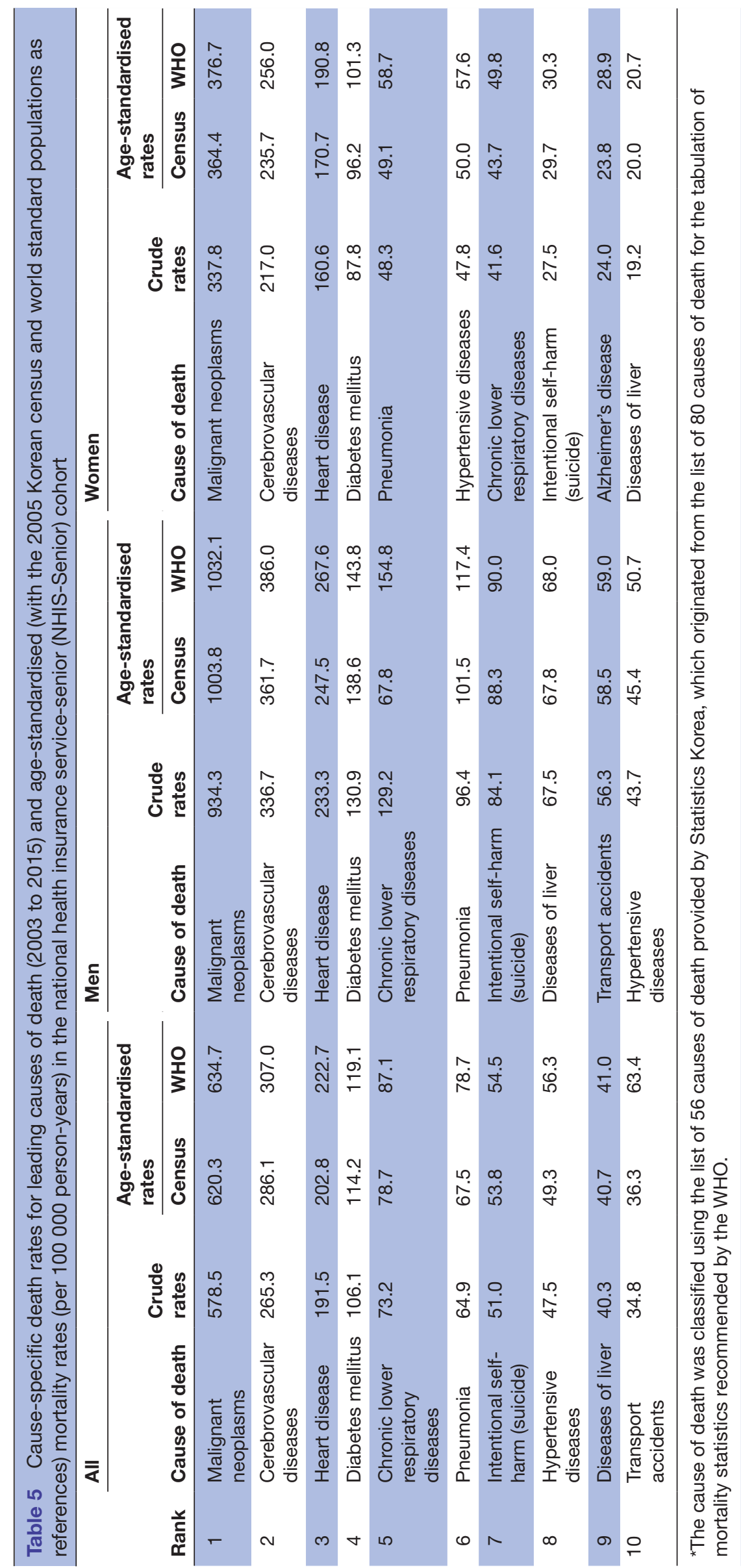




\section{Strengths and limitations}

The NHIS-Senior cohort provides nationally representative cohort data regarding the elderly population in Korea. The NHIS-Senior cohort has several strengths. First, it provides reliable data based on a large sample $(\mathrm{n}=558$ 147) and a long duration of follow-up (from 2002 to 2015), and is representative of the entire elderly population. Second, due to the characteristics of the national administration data, the NHIS-Senior cohort has a very low attrition rate and includes more valid and accurate information than self-reported questionnaire-based survey data, especially for socio-economical status, healthcare utilisation and death information. Third, it is possible to analyse the pre-hospital stages of disease using information from the health screening programme and long-term care services.

The NHIS-Senior cohort has certain limitations. First, some of the subjects did not participate in the health screening programme or receive long-term care services due to issues regarding service eligibility. Therefore, there is a possibility of selection bias in health screening information. Second, variables on health behaviours are limited since those data were obtained from self-reporting questionnaires in nationwide health screenings. Third, the disease codes might not accurately reflect patients' medical conditions, as they are sometimes exaggerated to receive reimbursement due to fee-for-service payment system. ${ }^{24}$

Contributors YIK, YYK, JLY, CWW, SJ, HK contributed to the conception of this article. YYK, JHP, BRP were involved in manuscript writing and revision. YYK, SH, $\mathrm{KDC}, \mathrm{SB}, \mathrm{EL}, \mathrm{SYP}, \mathrm{KL}$, DL were involved in data analysis and interpretation. All authors read and approved the final manuscript.

Funding This work was supported by National Health Insurance Service (NHIS) in Korea.

Competing interests None declared.

Patient consent for publication Not required.

Provenance and peer review Not commissioned; externally peer reviewed.

Data sharing statement No additional data.

Open access This is an open access article distributed in accordance with the Creative Commons Attribution Non Commercial (CC BY-NC 4.0) license, which permits others to distribute, remix, adapt, build upon this work non-commercially, and license their derivative works on different terms, provided the original work is properly cited, appropriate credit is given, any changes made indicated, and the use is non-commercial. See: http://creativecommons.org/licenses/by-nc/4.0/.

\section{REFERENCES}

1. Organisation for Economic Co-operation and Development. Pensions at a Glance 2015: OECD and G20 Indicators: OECD, 2015.

2. Korea S. Population Projections for Korea: 2015-2065. Daejeon: Statistics Korea, 2016.
3. Organisation for Economic Cooperation and Development. Facing the future: Korea's family, pension and health policy challenge. Paris: OECD, 2007.

4. Peabody JW, Gertler PJ, Yang BM, et al. 12. Financing health care for the elderly: will an aging population end 'health for all' in South Korea? The Economics of Health Care in Asia-Pacific Countries 2002:241.

5. Chung $\mathrm{KH}$. The living profile and welfare service needs of older persons in Korea. Seoul: Korean Institute for Health and Social Affairs, Ministry of Health and Welfare, 1998.

6. Park MH. The living profile and welfare service needs of older persons in Korea. Seoul: Korean Institute for Health and Social Affairs, Ministry of Health and Welfare, 2008.

7. National Health Insurance Services. 'National Health Insurance Act' \& 'Act on Long-term Care Insurance for Senior Citizens': National Health Insurance Corporation, 2009.

8. Kwon S. Future of long-term care financing for the elderly in Korea. $J$ Aging Soc Policy 2008;20:119-36.

9. Cheol Seong S, Kim YY, Khang YH, et al. Data Resource Profile: The National Health Information Database of the National Health Insurance Service in South Korea. Int J Epidemiol 2017;46:799-800.

10. Seong SC, Kim YY, Park SK, et al. Cohort profile: the National Health Insurance Service-National Health Screening Cohort (NHIS-HEALS) in Korea. BMJ Open 2017;7:e016640.

11. Ministry of Foreign Affairs. Statistics on Korean emigration registration. Seoul: Ministry of Foreign Affairs.

12. Christensen S, Johansen MB, Christiansen CF, et al. Comparison of Charlson comorbidity index with SAPS and APACHE scores for prediction of mortality following intensive care. Clin Epidemiol 2011;3:203.

13. National Health Insurance Service (NHIS). National Health Screening Statistical Yearbook. Seoul: National Health Insurance Service.

14. Hwang D, Kim S, Choi H, et al. Calcium-Channel Blockers and Dementia Risk in Older Adults- National Health Insurance Service Senior Cohort (2002-2013). Circ J 2016;80:2336-42.

15. Kim JH, Lee Y. Dementia and death after stroke in older adults during a 10-year follow-up: results from a competing risk model. $J$ Nutr Health Aging 2018;22:297-301.

16. Kim H, Chun HW, Kim S, et al. Longitudinal study-based dementia prediction for public health. Int $J$ Environ Res Public Health 2017; 14:983.

17. Kim SY, Kim S, Choi SE, et al. Number of daily antihypertensive drugs and the risk of osteoporotic fractures in older hypertensive adults: National health insurance service - Senior cohort. $J$ Cardiol 2017;70:80-5.

18. Bu N, Kim S, Choi H, et al. Pre-discharge rehabilitation after hip surgery reduces 30 -day readmissions in older adults: National Health Insurance Service-Senior Cohort (2007-2012). Eur Geriatr Med 2017;8:430-4.

19. Kim H, Yoon JL, Lee A, et al. Prognostic effect of body mass index to mortality in Korean older persons. Geriatr Gerontol Int 2018; $18: 538-46$.

20. Lee S-H, Kim D-H, Lee C-W, et al. Retrospective Study of the Association between Waist Circumference and Mortality in the Korean Elderly. Korean J Clin Geri 2017;18:36-43.

21. Lee TW, Yim E, Cho E, et al. Cognitive function, behavioral problems, and physical function in long-term care insurance beneficiaries with dementia in South Korea: comparison of home care and institutional care services. J Am Geriatr Soc 2014;62:1467-75.

22. Jung W-S, Yim E-S. The Effect on Health Care Utilization of the Non-Use of Beneficiaries of Long-Term Care Insurance Service around of Geriatric Hospital's Medical Cost -. Journal of the Korea Academia-Industrial cooperation Society 2015;16:7463-73.

23. Ahmad OB, Boschi-Pinto C, Lopez AD, et al. Age standardization of rates: a new WHO standard. Geneva: World Health Organization, 2001:9.

24. Wilchesky M, Tamblyn RM, Huang A. Validation of diagnostic codes within medical services claims. J Clin Epidemiol 2004;57:131-41. 